\title{
Preliminary Result: Identification of Landslides using Electrical Resistivity Tomography Case Study Mt. Betung
}

\author{
Erlangga Ibrahim F. ${ }^{1}$, Hikhmadhan Gultaf ${ }^{2}$, Hendra Saputra ${ }^{2}$, Lea Kristi Agustina ${ }^{3}$, \\ Virgian Rahmanda ${ }^{1}$, Cahli Suhendi ${ }^{1}$, M. R.P. Sudibyo ${ }^{1}$, Reza Rizki ${ }^{1}$.
}

${ }^{1}$ Geophysical Engineering, Department of Industrial Technology, Institut Teknologi Sumatera, South Lampung, Indonesia

${ }^{2}$ Geology Engineering, Department of Industrial Technology, Institut Teknologi Sumatera, South Lampung, Indonesia

${ }^{3}$ Geomatemathics Engineering, Department of Industrial Technology, Institut Teknologi Sumatera, South Lampung, Indonesia

\begin{abstract}
Institut Teknologi Sumatera (ITERA), ITB and local governments had been cooperated in establishing an astronomy observatory of ITERA Lampung (OAIL), which was located at Mt. Betung in the Pasawaran area. Geological setting of this area showed that the dominant lithology of Mt. Betung is pyroclastic, andesite, and breccia rocks. These volcanic deposits have the potential to move the materials down-slope by the force of gravity, steep slope, and high water-content. We have investigated some area with the potential of a landslide along OAIL construction area, which may be the cause of the landslip as well. We applied electrical resistivity tomography to analyse the electrical properties of the subsurface soil and determine the vulnerable area of the landslide. The result indicated that the area is divided into high resistivity at the top of the soil and low resistivity below. These high resistivity numbers are caused by pyroclastic flow while the lower one is caused by fracture-filled, mostly with water and clay.
\end{abstract}

Keywords: electrical resistivity tomography, landslide, OAIL, Mt. Betung

\section{Introduction}

ITERA cooperates with ITB and Lampung Governments to set up an astronomy laboratory namely Astronomy Observatorium of ITERA Lampung (OAIL) which will be constructed at Mt. Betung, located at the North-West of Lampung City around Pesawaran District and with an elevation of 1.240 mdpl to 1640 mdpl. Meanwhile, OAIL will be placed at the South - West from the top of Mt. Betung with the elevation of around $1.000 \mathrm{~m}$. OAIL aimed to be one of the largest astronomy laboratories in in Indonesia.

A landslide occured due to some complex field of forces which are activated on a mass of rock or soil, mostly caused by increasing of shear stress as well as decreasing of material strength on the slope. Mt. Betung is categorised as a pyroclastic flow, proven by pyroclastic deposits as a dominant rock surrounding the area. Some case studies showed that pyroclastic soil is contributing to landslide occurrence. [1].

In this paper, we investigated a vulnerable area of landslide using high resolution 2D of electrical resistivity tomography. These methods play important role in exploring unstable slope in order to provide information of how electrical properties distributed in the depth. Electrical properties of soils 
and rock are mainly dependent on water content, which crucially influences slope stability [1]. From these electrical properties, we could investigate lithology and determine potential landslide in the area. The aims of this study to understand the potential occurrence of a landslide in the surrounding of OAIL construction and to contribute in hazard analysis for OAIL building.

\section{Electrical Tomography Resistivity Method}

The geo-electrical method is one of geophysics method to investigate subsurface electrical properties by injecting an electric current to the subsurface and recording the responds in the surface. Generally, a geo-electrical method is implementing ohm's law, where the resistance depends on resistivity properties and geometry factor of the material. Geometry factor is a configuration of the electrode current and voltage in the acquisition.

\section{Data acquisition}

The acquisition of electrical resistivity tomography located at the area of OAIL building construction. The building was placed between two valleys and on the elevation of 930 to $950 \mathrm{mdpl}$ (Figure 1.). Geoelectrical line acquisition was chosen by considering slope with the length $180 \mathrm{~m}$ in direction of SE NW and interval between electrodes are 6 meters. This line is in the left side construction area with a slope of around 22 to 50 degree and at an elevation of around 904 to $920 \mathrm{mdpl}$. We implemented a dipole - dipole configuration to delineate the distribution of electrical properties in the subsurface.
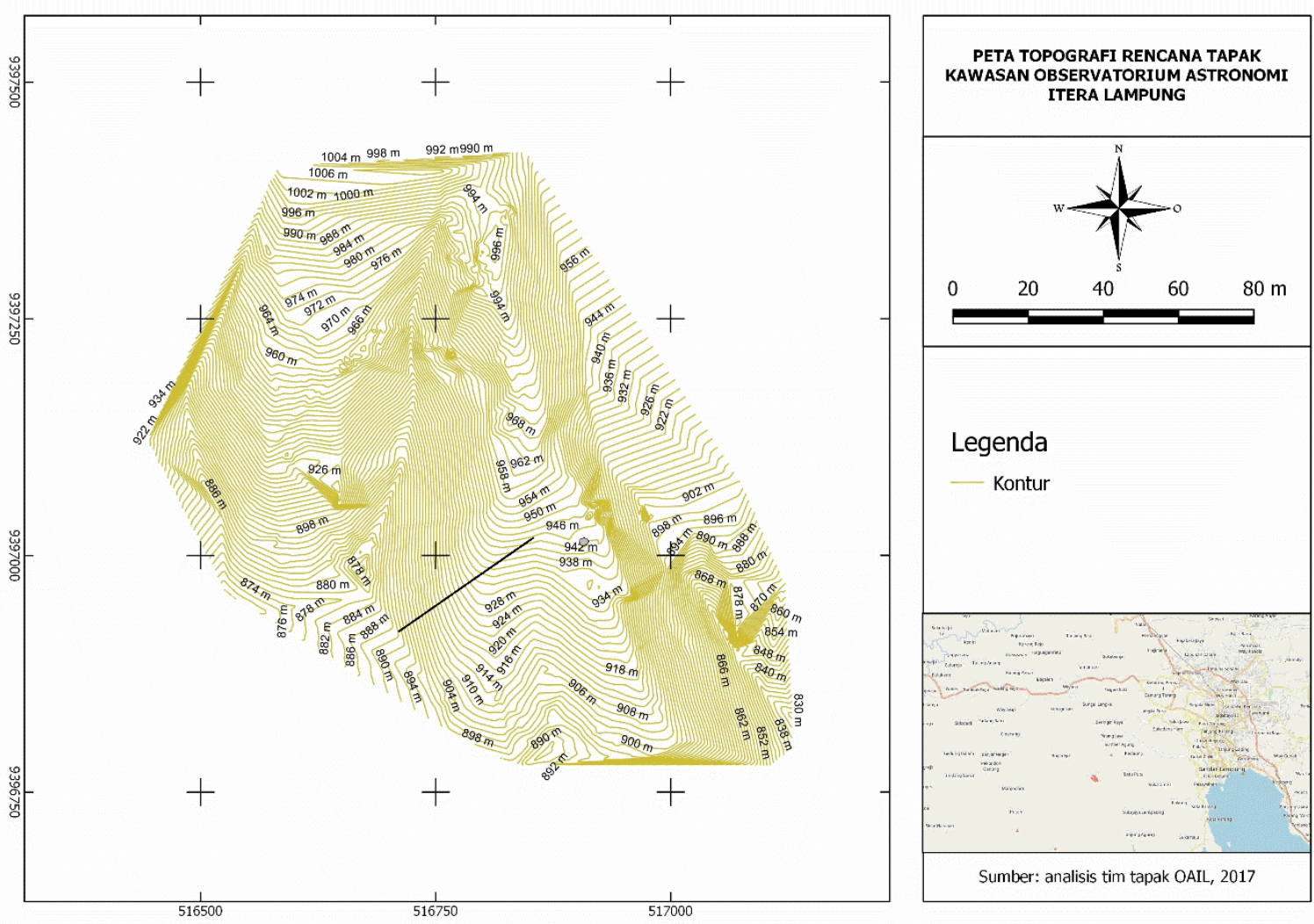
Figure 1. The location of OAIL construction in Mt. Betung, the black line indicated as geo-electrical line survey with length $180 \mathrm{~m}$.

The line acquisition located at the valley on the left side of the construction area and at the coffee field. The acquisition conducted at the dry season and the condition of the top soil were dry.

\section{Result and Discussion}

A landslide occurs when the soil loses some of its material strength due to the water content in the soil or an increase of load in the soil. Electrical resistivity tomography can be delineated landslide slip surface using electrical properties of the soil in the subsurface. Electrical properties depend on the water content in the soil. This information can also be used to identify lithology of the subsurface.

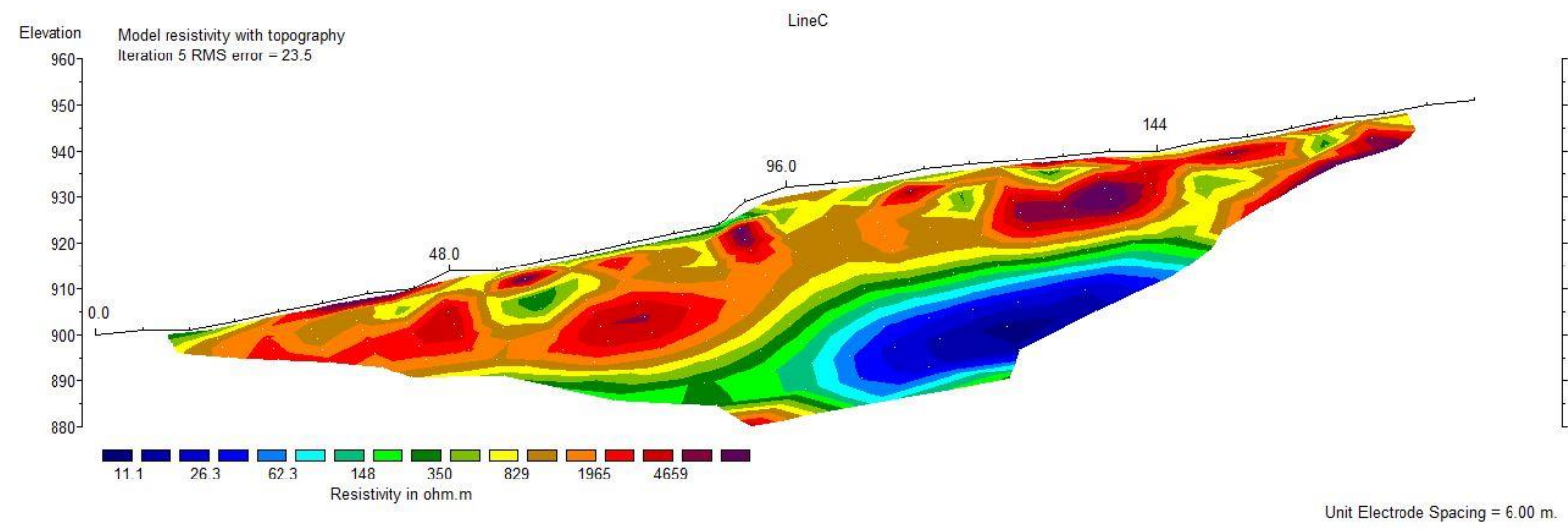

Figure 2. Electrical Resistivity Tomography (ERT), high resistivity $>140 \Omega \mathrm{m}$ and low resistivity $<80$ $\Omega \mathrm{m}$

Figure 2 shows the result of electrical resistivity tomography, high resistivity identified by red - purple colour. The lower elevation towards the direction of SW and the highest direction towards NE. High resistivity indicated low saturated water and low permeability while the low resistivity indicated high saturated water and has high permeability.

\section{Conclusion}

The conclusion of this research:

1. We may use the electrical resistivity method in order to determine numbers of layers in the subsurfaces by the electrical properties response.

2. Lower porosity rocks with high resistivity response are shown by red colour due to pyroclastic deposits. On the other hand, we predicted lower resistvity response is caused by the volcanic deposits with high-saturated water, which indicated as clay-filled.

3. The potential landslide slip surfaces estimated as Creep Type which is in the boundary of high and low resistivity area. Creep is the slow downslope movement of weathered soil particles on the slope. 
ICOSITER 2018 Proceeding

Journal of Science and Applicative Technology

\section{References}

[1] Plegari, E., Cataudella, V., Di Maio, R., Milano, I., Nicodemi, M., Soldovieri, M.G., "Electrical Resistivity Tomography and Statistical Analysis in Landslide Modelling: A Conceptual Approach," Journal of Applied Geophysics, 68, 151 - 158, 2009.

[2] Asriza, Supriyanto, Kristyato, T.H.W., Indra, T.L., Syahputra, R., Tempessy, A.S., "Determination of the Landslide Slip Surface Using Electrical Resistivity Tomography (ERT) Technique," Workshop on World Landslide Forum 2017, Advancing Culture of Living with Landslides, pp 53 - 60.

[3] Lapenna, Vincenzo, Perrone, Angela, Piscitelli, Sabatino "Electrical Tomography for Landslide Monitoring: State - of the art and an overview of the recent result in Southern Italy," EMSEV 2012, pp $1-13$.

[4] Shirley, Andrew, "Earth Retaining Structures in Areas of Landslide," Civil \& Structural Pane 2007.

[5] Heradian, Ezra Andwa, Arman, Yudha, "Pendugaan Bidang Gelincir Tanah Longsor di Desa Aruk Kecamatan Sjingan Besar Kabupaten Sambas dengan Menggunakan Metode Tahanan Jenis," PRISMA FISIKA, Vol III, 2015, Hal. 56-61.

[6] Santoso, Budi "Penerapan Metode Geolistrik 2D untuk Identifikasi Amblasan Tanah dan Longsoran di jalan Tol Semarang - Solo Km $5^{+400}-5^{+800}$, "Spektra: Jurnal Fisika dan Aplikasinya, Vol 1, 2016. 